\title{
Consolidation and warpage deformation finite element analysis of
}

\author{
filament wound tubes
}

\author{
Jun Li ${ }^{* a}$ Chensong Dong ${ }^{\mathrm{b}}$ Shenshen Chen ${ }^{\mathrm{a}}$ \\ ${ }^{a}$ Department of Engineering Mechanics, Tsinghua University, Beijing 100084, \\ PR China \\ ${ }^{b}$ Department of Mechanical Engineering, Curtin University of Technology, Perth, WA \\ 6845, Australia
}

\begin{abstract}
This paper presents a process model for simulating the manufacturing process of prepreg filament wound composite tubes developed based on the finite element analysis. The model relates the process variables, such as degree of cure, viscosity, material property and temperature etc., to the parameters characterizing (residual stresses, warpage deformation) the composite tube and the mandrel. From the simulating results, several important trends in both the data and model are observed (1) Low temperature will go with low reaction rate and the reaction starts under low temperature will later compared with high temperature; (2) The results using CHILE model after demolding will smaller than the one using linear elasticity which assumes a stress-free prior to cool-down. After the mandrel (mold) is removed, some residual stresses, especially hoop stress will be released. (3) Remarkable stress concentration appeared in the transition zone between the boss and cylinder. In order to prevent the structural failure due to interlaminar shear or delamination, both the outer surface of the cylinder and the inner of the boss should have the same ply orientation angle.
\end{abstract}

${ }^{*}$ Corresponding author. Tel.:+86-10-51537964;

E-mail address: njlijun@163.com 
Keywords: Filament wound; Viscosity and degree of cure; Residual stresses; Warpage deformation;

\section{Introduction}

Filament winding is widely used in the aerospace industry to make structures such as launch vehicles. In a filament winding process, resin-impregnated fibers are wrapped around a rotating surface or mandrel (mold) at predefined angles. The desired mechanical properties and performance of the structure can be achieved by adjusting the winding angle. There are two different winding methods [1]: (1) wet winding, in which fibers are passed through a resin bath and wrapped around a rotating mandrel; (2) prepreg winding, in which the prepreg tows are wrapped around a rotating mandrel. In real manufacturing, the mandrels may be removed or not after curing depending on the requirement. At the same time, due to the part is too large, it is very difficult to rotate the mandrel, so the winding tension usually in the hoop direction only.

As the size of the composite structures used in the aerospace industry increases higher manufacturing cost is incurred. One of the reasons is associated with the warpage induced in the manufacturing process. Hence, effective warpage control is crucial for the cost-effective realization of large filament wound composite structures. Many studies have been carried out to study the warpage of filament wound composites structures. In early works of Springer and his co-workers [2-5], a filament winding process model was developed based on detail theoretical analysis. Their model consisted of three sub-models, one for resin flow and fiber motion, one for cure kinetics and viscosity changes, and one for residual stresses. However, their model 
was based on the assumption of constant material properties. Mantell and her co-workers $[6,7]$ modeled the wet filament winding process as a special case of squeezed sponge model. Their work considered the effect of resin curing/gelation; the effects of resin mixing between adjacent layers and modified stiffness formulation. Theoretical methods were also developed for the warpage of composite cylinder and the design methodologies [8, 9]. Cai et al. [10] developed a fiber motion model that combined Darcy’s flow and nonlinear spring compaction. Kokan et al. [11] developed a viscoelastic filament winding model to predict the resulting residual stress state, and an elasticity solution to the stress and displacement of the winding cylinders. Gray [12] used FEM to study the composite overwrapped pressure vessel. Seber et al. [13] studied a process for shape optimization of filament wing pressure vessels.

However, they are all not research relationship among the processing conditions including the mold (mandrel), temperature, warpage deformation, and residual stresses etc. And they all assumed constant material properties. In this work, a methodology is accomplished to understanding the underlying causes of warpage deformation, and considered that the material properties are the function of degree of cure. Utilizing this basic understanding, methods for reducing and eliminating the warpage are developed.

\section{Modeling approach of filament winding}

\subsection{Thermo-chemical model}

The thermo-chemical model describes the heat generation, temperature, cure state, and viscosity during the curing process. The thermal component of the 
thermo-chemical model [2] is described by:

$\rho c \frac{\partial T}{\partial t}=\frac{1}{r} \frac{\partial}{\partial r}\left(k_{r} r \frac{\partial T}{\partial r}\right)+\frac{\partial}{\partial z}\left(k_{z} \frac{\partial T}{\partial z}\right)+\dot{\Phi}$

where $\rho$ denotes the density of the composite; $c$ is the specific heat; $T$ is temperature; $k_{r}$ and $k_{z}$ are the radial and axial thermal conductivities, respectively; and $\dot{\Phi}$ represents the instantaneous heat generated by the cross-linking polymerization of the resin, $\dot{\Phi}$ is assumed to be proportional to reaction rate and given by the follow expression [14]:

$\dot{\Phi}=\rho_{r} V_{r} H_{R} \frac{d \alpha}{d t}$

where $\rho_{r}$ is the density of the resin; $V_{r}$ represents the volume fraction of the resin; $H_{R}$ is the total heat liberated for complete cure; $\frac{d \alpha}{d t}$ is designated as the cure rate and it is a function of temperature and degree of cure. In this paper, the following empirical formula is used [14]:

$\left\{\begin{array}{l}\frac{d \alpha}{d t}=\left(k_{1}+k_{2} \alpha\right)(1-\alpha)(0.47-\alpha) \quad \alpha \leq 0.3 \\ \frac{d \alpha}{d t}=k_{3}(1-\alpha) \quad \alpha>0.3\end{array}\right.$

$k_{1}, k_{2}$ and $k_{3}$ are defined by Arrhenius rate expressions as [15]:

$k_{i}=A_{i} \exp \left(\frac{-\Delta E_{i}}{R T}\right) \quad(i=1,2,3)$

where $R=8.31 \mathrm{~J} / \mathrm{Mol} \cdot \mathrm{K}$ is the universal gas constant, $A_{i}$ is the pre-exponential coefficient, and $\Delta E_{i}$ is the activation energy. $\alpha$ can be measured by a standard differential scanning calorimeter (DSC).

The initial condition is:

$T=T_{0}, \alpha=0$ at $t=0$ 
And the boundary conditions are:

$\left\{\begin{array}{l}T=T_{\infty} \\ P=P_{\infty}\end{array}\right.$ on $\Gamma_{1}$

which are specified at all the manufacture process.

Once the temperature $T$ and the degree of the cure $\alpha$ are known, the viscosity can be calculated from an expression of the form:

$\mu=f(\alpha, T)$

In this study, the following expression of viscosity is used [15]:

$\mu=\mu_{\infty} \exp \left(\frac{U}{R T}+K \alpha\right)$

where $\mu_{\infty}, U$ and $K$ are constants independent of the temperature, $\mu$ denotes the viscosity of the resin. And the specific parameters of cure kinetics and viscosity are shown in Table 1.

\subsection{Material properties (CHILE Model)}

The CHILE (cure hardening instantaneously linear elastic) model is used to analyses the polymer as it goes through the curing process [14]. The composite constituents used in this study are AS4 fiber and 3501-6 resin. The properties of AS4 fiber are assumed to be independent of the temperature changed. The elastic modulus of 3501-6 is given by:

$$
E_{m}=\left(1-\alpha_{\text {mod }}\right) E_{m}^{0}+\alpha_{\text {mod }} E_{m}^{\infty}+\gamma \alpha_{\text {mod }}\left(1-\alpha_{\text {mod }}\right)\left(E_{m}^{\infty}-E_{m}^{0}\right)
$$

where:

$\alpha_{\text {mod }}=\frac{\alpha-\alpha_{\mathrm{gel}}^{\text {mod }}}{\alpha_{\text {diff }}^{\text {mod }}-\alpha_{\text {gel }}^{\text {mod }}}$ and $(-1<\gamma<1)$

$E_{m}^{0}$ and $E_{m}^{\infty}$ are the assumed fully uncured and fully cured temperature dependent 
resin modulus, respectively. $\alpha_{\text {gel }}^{\text {mod }}$ denotes the beginning point of resin gelation and $\alpha_{\text {diff }}^{\text {mod }}$ represents the point of fully cured with diffusion limitation. The term $\gamma$ is introduced to quantify the competing mechanism between stress relaxation and chemical hardening. In this study, $E_{m}^{0}$ and $E_{m}^{\infty}$ are assumed constants and $\gamma=0$. It is also assumed that $\alpha_{\text {gel }}^{\text {mod }}=0$ and $\alpha_{\text {diff }}^{\text {mod }}=1$. Then the material properties of unidirectional plies are determined by the mechanical properties of their constituent resin and fiber using micromechanics equations from Bogetti et al. [16].

\subsection{Winding tension stresses}

Since the fibers are under tension, there is a pressure difference in the resin across the fiber sheet. The fiber bed compaction caused by an external pressure $p_{0}$ imposed on a $k$ layered cylinder can be found by following an elasticity approach. From the physics of winding [6], the pressure applied by the $k+1$ layer to the outside of the previously wound layer is related to the layer winding conditions:

$$
p_{0}=\frac{F^{k+1} \sin ^{2} \phi}{r_{f}^{k+1} w^{k+1}}
$$

where $F$ is the initial fiber tension, $\phi$ is the winding angle and $w$ is the tow band width.

\subsection{Mold-part interface model}

To model the mechanical interaction between the mold and the part, a single shear layer of low modulus elements are incorporated into the FE mesh between the mold and the part. By adjusting the modulus of this shear layer, the amount of stress transferred between the mold and part could be tailored. By setting the in-plane and shear muduli of the shear layer very low, $\sim 10^{4} \mathrm{~Pa}$ [17] (while maintain the out of 
plane modulus equal to that of the mold material, to prevent the part from penetrating the shear layer) the response of a compliant interface could be approximated. It should be noted that the shear layer is considered to be part of the mold and is removed in the demolding calculation and the thickness is equal to the single ply thickness.

\section{FE implementation}

The analytical models are utilized in a commercial program ABAQUS to perform the FE analysis for the filament winding process. Fig.1 shows the flow chart of the analysis process. The meshing is made ply by ply which means in the radial direction an element on each floor. And this volumetric contraction of the resin is converted to a thermal expansion coefficient and added to the elastic thermal expansion. A value of the volumetric shrinkage range $\left(V_{c}=3 \%\right)$ is used.

\section{Numerical example}

A cylinder made of AS4/3501-6 prepreg tows is wound on 4mm thick, 52mm outside diameter and 75mm long aluminum mandrel (Fig 2). The composite cylinder consists of 16 plies of AS4/3501-6 prepreg tape with a [(90/0)2/45/-45/0/90]s lay up. The boss consists of 6 plies of AS4/3501-6 prepreg tape with a [90/0/-45/45/0/90] or [0/90/-45/45/0/90] lay up. The single ply thickness of the prepreg is $0.25 \mathrm{~mm}$. The band winding tension of the cylinder decreased from $48 \mathrm{~N}$ to $38 \mathrm{~N}$, and the band winding tension of the boss decreased from $30 \mathrm{~N}$ to $28 \mathrm{~N}$. In this calculation, the band winding tension is converted to the initial stresses added the element. The curing temperature and pressure employed in the calculation are shown in Fig 3. The entire 
inside surface of the mandrel and the entire outside surface of the composite tube are assumed to be at this temperature and pressure. Additional relevant processing parameters and material properties used in the calculation are listed in Table 2, 3.

\subsection{Viscosity and cure kinetics of the resin}

In this study, five different second hold temperatures are chosen. For each temperature, the degree of cure, viscosity and reaction rate of the resin inside the prepreg under different temperature are calculated using the thermo-chemical submodel. These numerical (model) results are shown in Figs.4-6.

Fig. 4 shows the variation of resin viscosity inside the prepreg as a function of the hold temperature under non-isothermal conditions. As can be seen from this graph, the viscosity variation curves are nearly identical under different hold temperature. As the temperature of the resin increases, the viscosity keeps decreasing until a temperature of about $412 \mathrm{~K}$ which correspond the liquid-solid transition point, and then the cure reaction starts which increases the viscosity exponentially.

The reaction rate of prepreg with 50.8\% 3501-6 resin as shown in Fig.5 It shows that the curing rate is a function of the second hold temperature. The formulation with $438 \mathrm{~K}, 448 \mathrm{~K}, 458 \mathrm{~K}, 468 \mathrm{~K}, 478 \mathrm{~K}$ follow the same curve. However, the reaction rate is relatively slower with lower hold temperature. And the degree of cure curve for all formulations follows the same law. However, the reaction for the lower hold temperature starts later compared with other formulation.

Fig.6 shows the evolution of the temperature at the center, the surface of the tube, and the center of the mold (mandrel) with the surface temperature (the second hold 
stage) of the composite under $458 \mathrm{~K}$. As indicates that the temperature at the center of the tube and the mandrel is close to the boundary condition (surface temperature), because the tube is very thin. For thick tubes, the temperature at the center will reaches a peak value [14].

\subsection{Warpage deformation and residual stresses}

The warpage deformation of the filament wound structures is mainly due to thermal and resin cure shrinkage anisotropic strain, exothermic chemical reaction of the resin, significant differences of CTE between composite materials and mold material, band winding tension, and other factors [14]. The following is an outline of the solution for the residual stresses and deformation in a multilayered orthotropic tube during cure after mold (mandrel) removed and all of these factors are considered. In the residual stresses calculated, the rigid displacement is constrained. From Figs. 7-8, it can be seen that the residual stresses with these two lay-ups are different. Remarkable difference is found for the hoop stress at the outer of the boss. The hoop stress of the boss is positive with [90/0/-45/45/0/90] lay-up, but it is negative with [0/90/-45/45/90/0] lay-up. Therefore, the ply stacking sequence plays a vital role for the residual stresses. Reasonable stacking sequence and winding tension should be selected based on specific process requirements. In order to prevent the structural failure due to interlaminar shear or delamination, both the outer surface of the cylinder and the inner of the boss should be lay up with the same ply orientation angle.

As can be seen from Fig. 9, the results are all axisymmetric, and the radial displacement in the inner of the tube is smaller than the outer of the tube. The reason 
is that the inner surface of the tube contacts with the mandrel, which is more stiffness than the tube.

Figs.10-12 show that a remarkable stress concentration appeared in the transition zone between the boss and cylinder. And after the mold (mandrel) removed, some residual stresses will be released, especially the hoop stress. At the same time, as can be seen that the results using linear elasticity which only consider the cool down stage is larger than the CHILE model results after demolding, but smaller than the results before demolding. So removed the mold (mandrel) which can remarkable reduce the warpage and deformation. It is also important to select suitable tool material for filament wound tube.

\section{Conclusions}

Because the application of filament winding technology for the manufacturing of pressure vessels is widely used in launch vehicles today, the quantitative evaluation of structure quality using filament winding technology will play a key role in designing and manufacturing of composite structures.

In this paper, first, the mechanism of the filament winding process is analyzed. An FEA model is developed for simulating the manufacturing process of filament wound thermoset composite tubes. The process model consists of a thermo-chemical submodel and a stress-strain submodel. A single shear layer is introduced to simulate the mold-part interface effect. In the stress-strain submodel, the variation of material parameters vs. the degree of cure is considered.. Main factors causing warpage deformation and residual stresses e.g. exothermic chemical reaction of the resin, curing shrinkage of resin, CTE mismatch between composite tube and mold, and band 
winding tension, are considered. In the numerical examples, the viscosity, degree of cure, and reaction rate are calculated with different hold temperatures, and the warpage deformation and residual stress of the tube are calculated. From the results the following conclusions can be drawn:

1. Resin reaction rate increases with temperature, and the reaction starts sooner at a higher temperature. The viscosity of resin decreases with temperature until around $412 \mathrm{~K}$. Resin reaction then begins and the viscosity increases exponentially.

2. The results from the CHILE model after demolding are smaller than those from the linear elasticity model which assumes a stress-free prior to cool-down. Remarkable stress concentration exists in the transition zone between the boss and the cylinder. After the mandrel (mold) is removed, some residual stresses, especially hoop stress will be released, and the warpage and deformation are reduced significantly.

3. The reasonable stacking sequence and winding tension should be selected nased on specific process requirements. In order to prevent the structural failure due to interlaminar shear or delamination, both the outer surface of the cylinder and the inner of the boss should be have the same ply orientation angle.

\section{References}

[1] Zhao LY, Mantell SC, Cohen D, et al. Finite element modeling of the filament winding process. Composite Structures 2001; 52:499-510.

[2] Lee SY, Springer GS. Filament winding cylinders: I. Process model. Journal of 
composite materials 1990; 24:1270-1298.

[3] Calius EP, Lee SY, Springer GS. Filament winding cylinders: II. Validation of the process model. Journal of composite materials 1990; 24:1299-1343.

[4] Lee SY, Springer GS. Filament winding cylinders: III. Selection of the process variables. Journal of composite materials 1990; 24:1344-1366.

[5] Calius EP, Springer GS. A model of filament wound thin cylinders. International journal of solids and structures 1990; 26(3):271-297.

[6] Banerjee A, Sun L, Mantell SC, Cohen D. Model and experimental study of fiber motion in wet filament winding. Composite Part A: applied science and manufacturing 1998; 29:251-263.

[7] Cohen D, Mantell SC, Zhao LY. The effect of fiber volume fraction on filament wound composite pressure vessel strength. Composites Part B: Engineering 2001; 32:413-429.

[8] Cai Z, Gutowski T, Allen S. Winding and consolidation analysis for cylindrical composite structures. Journal of composite materials 1992; 26:1374-1399.

[9]Kokan D, Gramoll K. Development of a viscoelastic filament-winding process model. AIAA/ASME/ASCE/AHS/ASC, 37th, Structures, Structural Dynamics, and Material Conference and Exhibit, Salt Lake City,UT,1996. p.1781-1787.

[10]Gray DL, Moser DJ. Finite element analysis of a composite overwrapped pressure vessel. AIAA/ASME/SAE/ASEE, 40th, Joint Propulsion Conference and Exhibit, Fort Lauderdale, Florida,2004. p.1-15.

[11]Kokan D, Gramoll K. Design and manufacture of composite cylinders. AIAA-94-1431-CP,1994. p.1013-1023.

[12] Meink TE, Huybrechts S, Shen MHH. Processing induced warpage of filament wound composite cylindrical shells. Journal of composite materials 2002; 
36:1025-1047.

[13] Seber G, Baker ML, et al. A process for shape optization of filament wound pressure vessels. AIAA/ISSMO Multidisciplinary Analysis and Optimization Conference, 11th, Portsmouth, Virginia,2006. p.1-14.

[14] Li J, Yao XF, Liu YH, Cen ZZ, Kou ZJ, Dai D. A study of the integrated composite material structures under different fabrication procressing. Composites Part A: applied and manufacturing.

[15] Costa VAF, Sousa ACM. Modeling of flow and thermo-kinetics during the cure of thick laminated composites. International Journal of thermal sciences 2003; 42:15-22.

[16] Bogetti TA, Gillespie JW. Process-induced stress and deformation in thick-section thermoset composite laminates. Journal of composite materials 1992; 26(5):626-660.

[17] Fernlund G, Rahman N, Courdji R, et al. Experimental and numerical study of the effect of cure cycle, tool surface, geometry, and lay-up on the dimensional fidelity of autoclave-processed composite parts. Composite Part A: applied science and manufacturing 2002; 33:341-351.

\section{Tables}

\section{Captions}

Table 1 Cure kinetics and viscosity constants [15].

Table 2 Material properties of AS4fiber, 3501-6Resin and mandrel [14].

Table 3 Thermal properties of composite materials and mandrel [14].

\section{Figures}

Fig.1 Flow chart of model process.

Fig.2. Configure of filament winding tube (mm).

Fig.3. Boundary condition of temperature and pressure. 
Fig.4. Viscosity of the composite under different temperature.

Fig.5. Reaction rate (a) and degree of cure (b) of the composite under different temperature.

Fig.6. Evolution of the temperature computed at center, surface and mold of the structure.

Fig.7. Residual stress contours of the tube with [90/0/-45/45/0/90] lay up for boss.

Fig.8. Residual stress contours of the tube with [0/90/-45/45/90/0] lay up for boss.

Fig.9. Deformation contours of the tube with [90/0/-45/45/0/90] lay up for boss.

Fig.10. Residual stresses versus axial position (L2) with [90/0/-45/45/0/90] lay up of boss.

Fig.11. Radial stress versus axial (L1) and radial position with [90/0/-45/45/0/90] lay up of boss.

Fig.12. Warpage deformation versus radial and axial position with [90/0/-45/45/0/90] lay up of boss.

\section{Tables}

Table 1

Cure kinetics and viscosity constants [15].

\begin{tabular}{ccc}
\hline Constant & Value & Unite \\
\hline$A_{1}$ & $2.102 \times 10^{9}$ & $\min ^{-1}$ \\
$A_{2}$ & $-2.014 \times 10^{9}$ & $\min ^{-1}$ \\
$A_{3}$ & $1.960 \times 10^{5}$ & $\mathrm{~min}^{-1}$ \\
$\Delta E_{1}$ & $8.07 \times 10^{4}$ & $\mathrm{~J} / \mathrm{mol}$
\end{tabular}




$\begin{array}{ccc}\Delta E_{2} & 7.78 \times 10^{4} & \mathrm{~J} / \mathrm{mol} \\ \Delta E_{3} & 5.66 \times 10^{4} & \mathrm{~J} / \mathrm{mol} \\ \mu_{\infty} & 7.93 \times 10^{-14} & \mathrm{~Pa} \cdot \mathrm{S} \\ U & 9.08 \times 10^{4} & \mathrm{~J} / \mathrm{mol} \\ K & 14.1 & \end{array}$

\section{Table 2}

Material properties of AS4fiber, 3501-6Resin and mandrel [14].

\begin{tabular}{|c|c|c|c|}
\hline & Constant & Value & Unite \\
\hline \multirow{7}{*}{ AS4Fiber } & $v_{12}=v_{13}$ & 0.2 & \\
\hline & $v_{23}$ & 0.25 & \\
\hline & $E_{1}$ & 210 & GPa \\
\hline & $E_{2}$ & 17.2 & $\mathrm{GPa}$ \\
\hline & $G_{12}=G_{13}$ & 27.6 & GPa \\
\hline & CTE1 & -0.9 & $\mu \varepsilon \phi^{\circ}$ \\
\hline & CTE2 & 7.2 & $\mu \varepsilon \phi^{\circ}$ \\
\hline \multirow{5}{*}{ 3501-6Resin } & $G^{u}$ & 1.185 & $\mathrm{GPa}$ \\
\hline & $G^{r}$ & 0.018 & GPa \\
\hline & $K^{u}$ & 3.556 & $\mathrm{GPa}$ \\
\hline & $K^{r}$ & 0.8 & $\mathrm{GPa}$ \\
\hline & CTE & 58 & $\mu \varepsilon \phi^{o}$ \\
\hline \multirow{3}{*}{ Mandrel } & $v$ & 0.3 & \\
\hline & $E$ & 39 & $\mathrm{GPa}$ \\
\hline & CTE & 21 & $\mu \varepsilon \phi^{\circ}$ \\
\hline
\end{tabular}


Table 3

Thermal properties of composite materials and mandrel [14].

\begin{tabular}{cccc}
\hline & Constant & Value & Unite \\
\hline$\rho_{p}$ & 1578 & $\mathrm{Kg} / \mathrm{m}^{3}$ \\
$C_{p}$ & 862 & $\mathrm{~J} / \mathrm{Kg} \cdot \mathrm{K}$ \\
AS4fiber/3501-6Resin & $K_{1}$ & 12.83 & $\mathrm{~W} / \mathrm{m} \cdot \mathrm{K}$ \\
& $K_{2}=K_{3}$ & 0.4135 & $\mathrm{~W} / \mathrm{m} \cdot \mathrm{K}$ \\
& $H_{R}$ & $198.6 \times 10^{3}$ & $\mathrm{~J} / \mathrm{Kg}$ \\
& $V_{r}$ & & \\
\hline Molume fraction & $\rho_{m}$ & 2700 & $\mathrm{Kg} / \mathrm{m}^{3}$ \\
& $C_{m}$ & 904.3 & $\mathrm{~J} / \mathrm{Kg} \cdot \mathrm{K}$ \\
& $K_{m}$ & 203 & $\mathrm{~W} \cdot \mathrm{K}$ \\
\hline
\end{tabular}




\section{Figures}

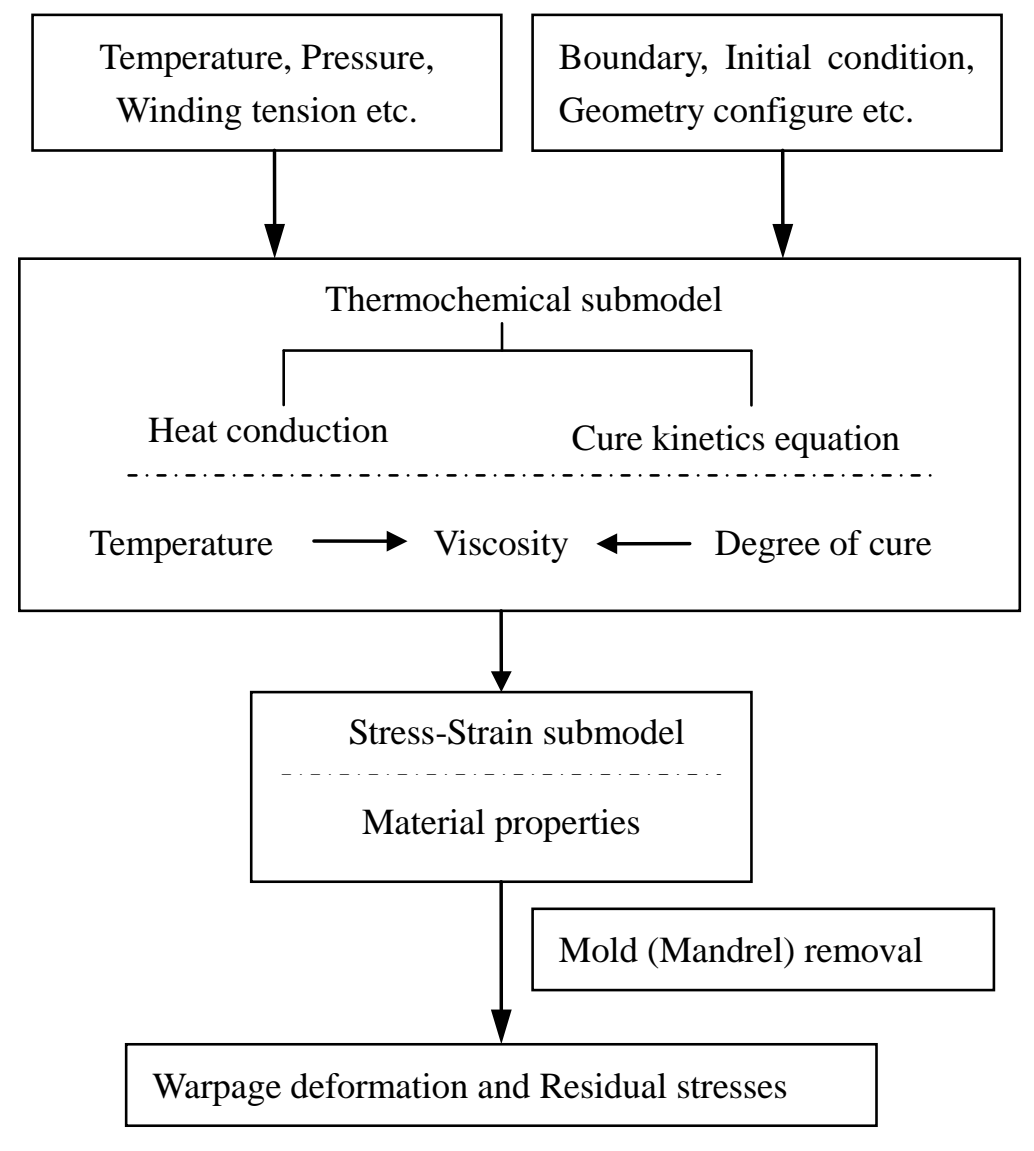

Fig.1 Flow chart of model process.

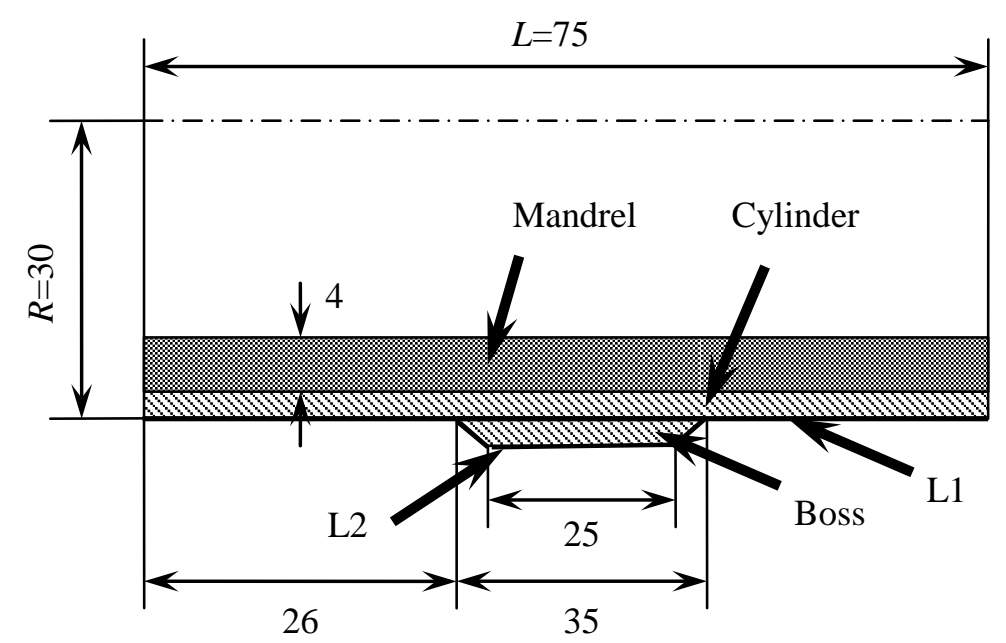

Fig.2. Configure of filament winding tube (mm). 


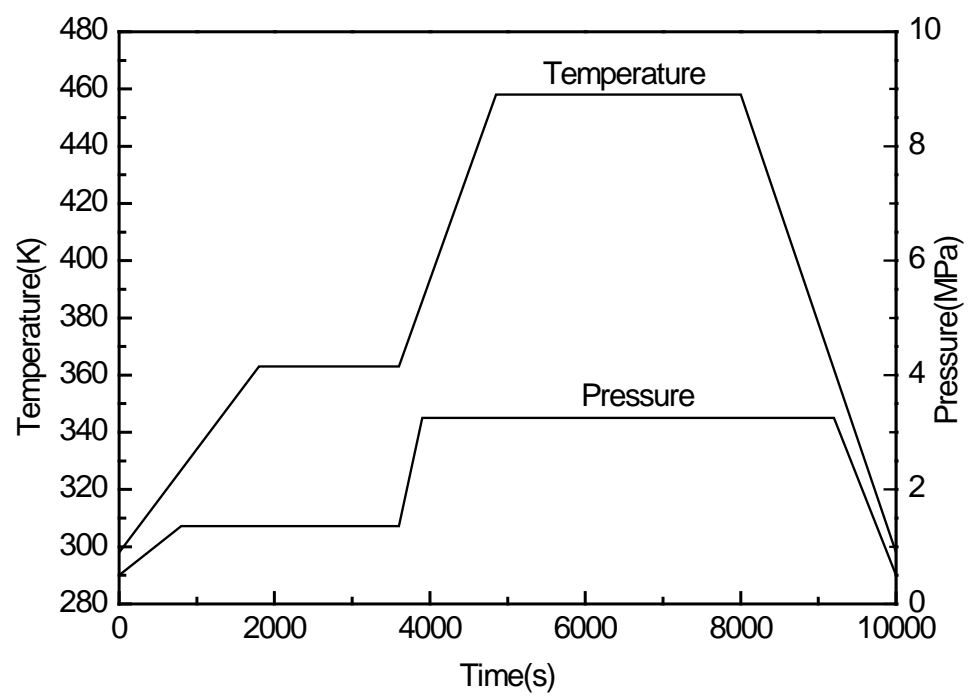

Fig.3. Boundary condition of temperature and pressure.

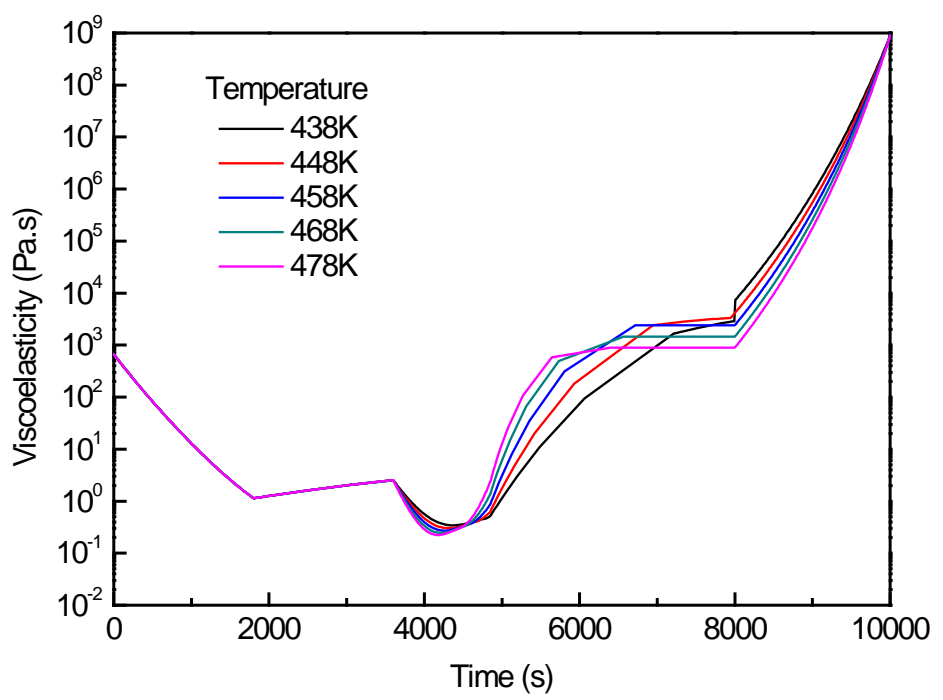

Fig.4. Viscosity of the composite under different temperature.
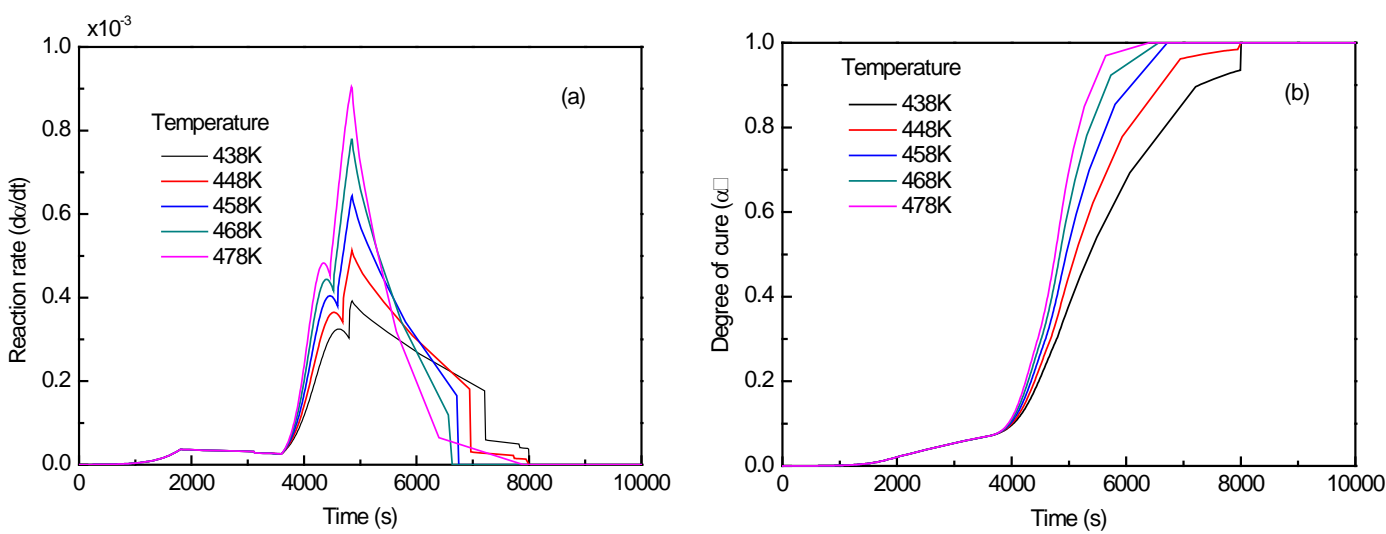

Fig.5. Reaction rate (a) and degree of cure (b) of the composite under different 
temperature.

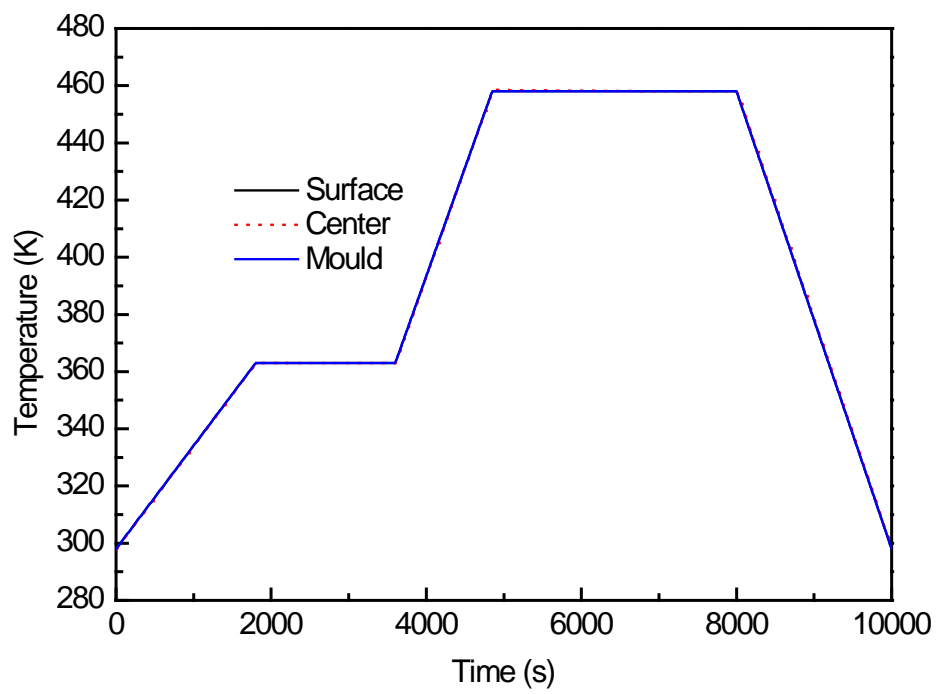

Fig.6. Evolution of the temperature computed at center, surface and mold of the structure.

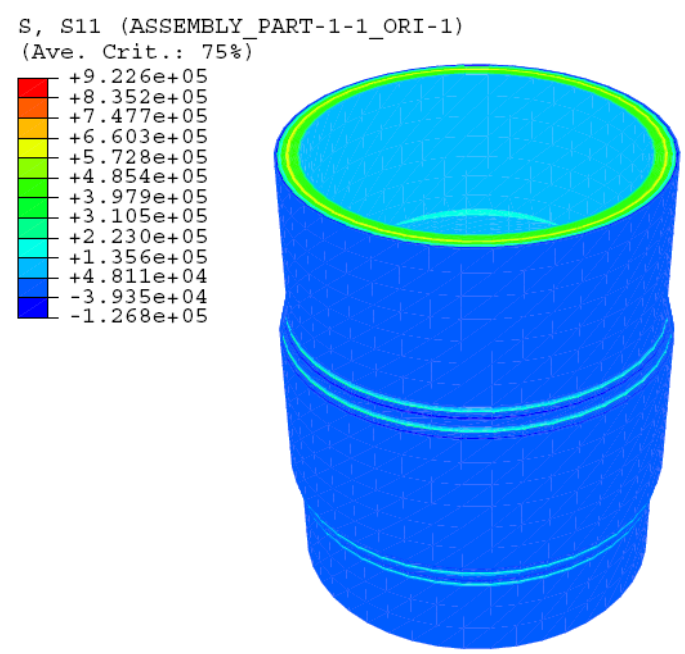

(a) Radial sress

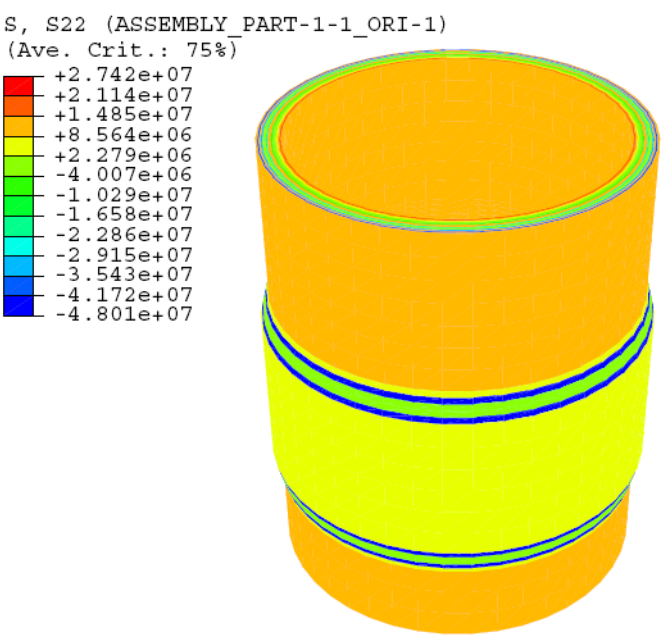

(b) Hoop stress

Fig.7. Residual stress contours of the tube with [90/0/-45/45/0/90] lay up for boss. 
S, S11 (ASSEMBLY_PART-1-1_ORI-1)
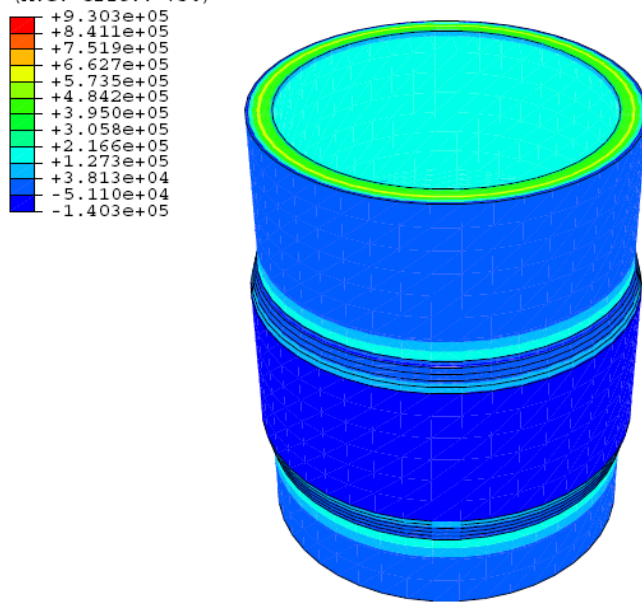

(a) Radial sress
S, S22 (ASSEMBLY_PART-1-1_ORI-1)
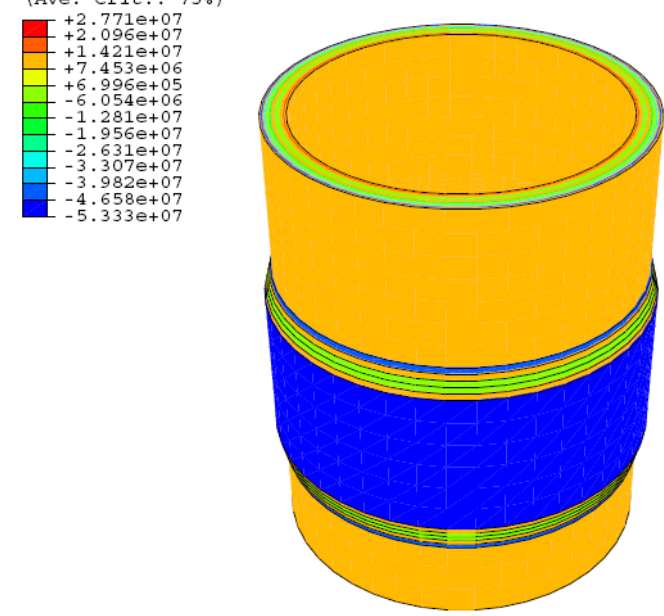

(b) Hoop stress

Fig.8. Residual stress contours of the tube with [0/90/-45/45/0/90] lay up for boss.

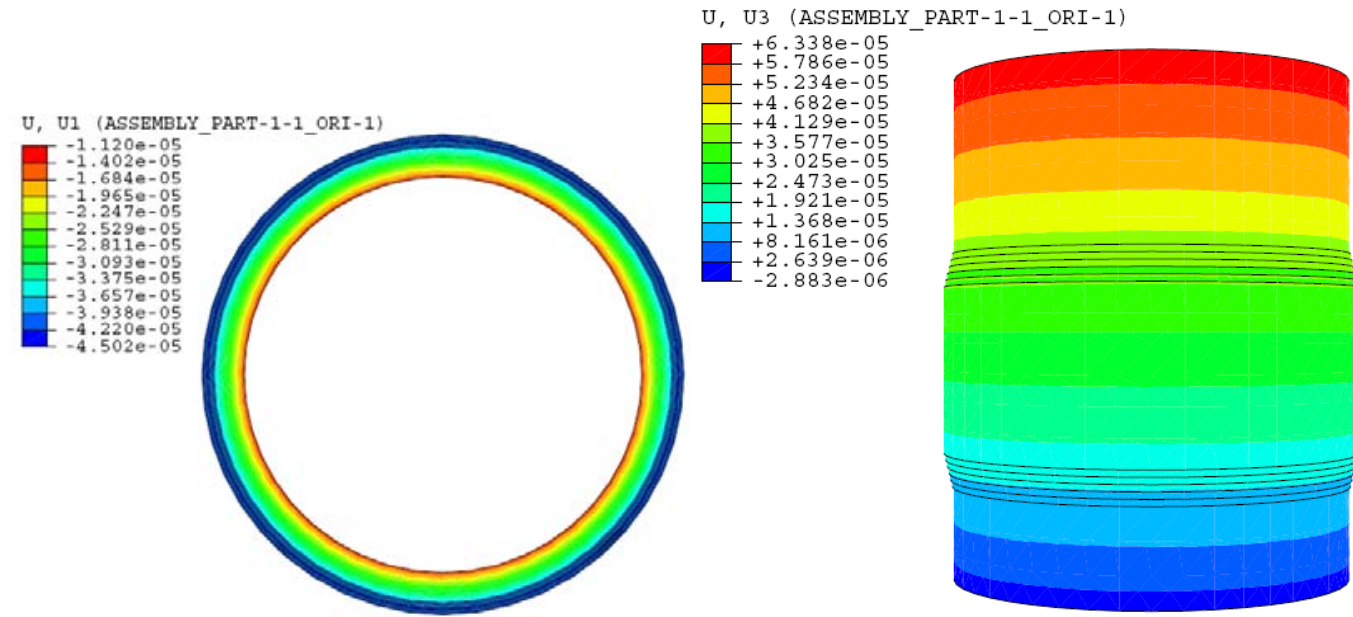

(a) Radial displacement

(b) Axial displacement

Fig.9. Deformation contours of the tube with [90/0/-45/45/0/90] lay up for boss
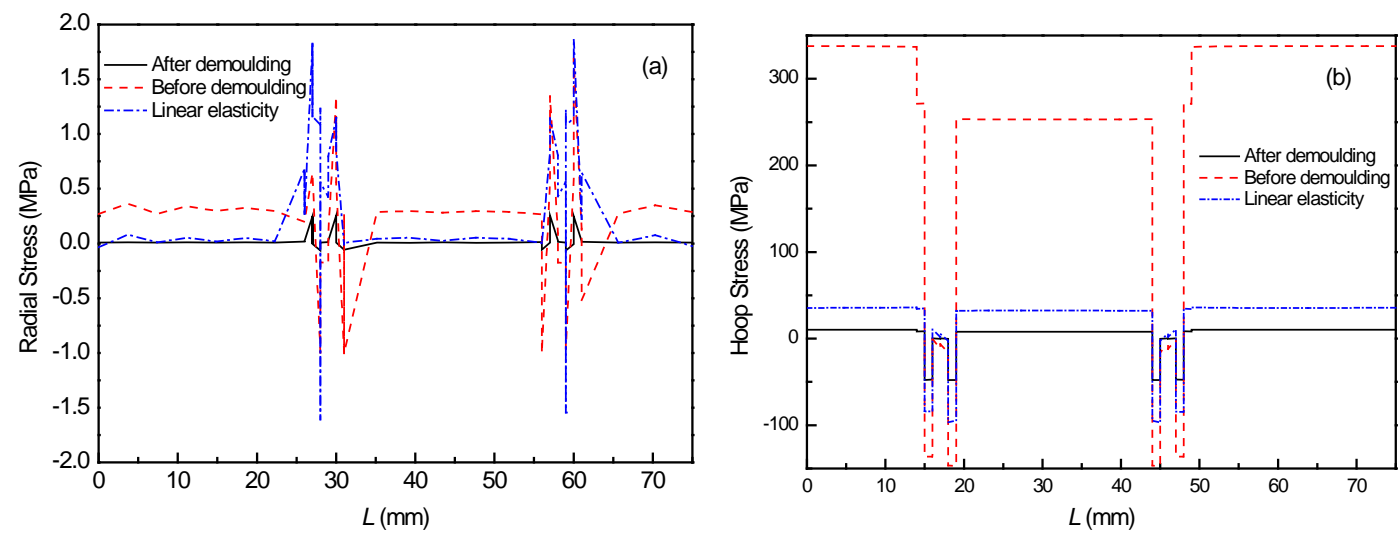

Fig.10. Residual stresses versus axial position (L2) with [90/0/-45/45/0/90] lay up 
of boss.
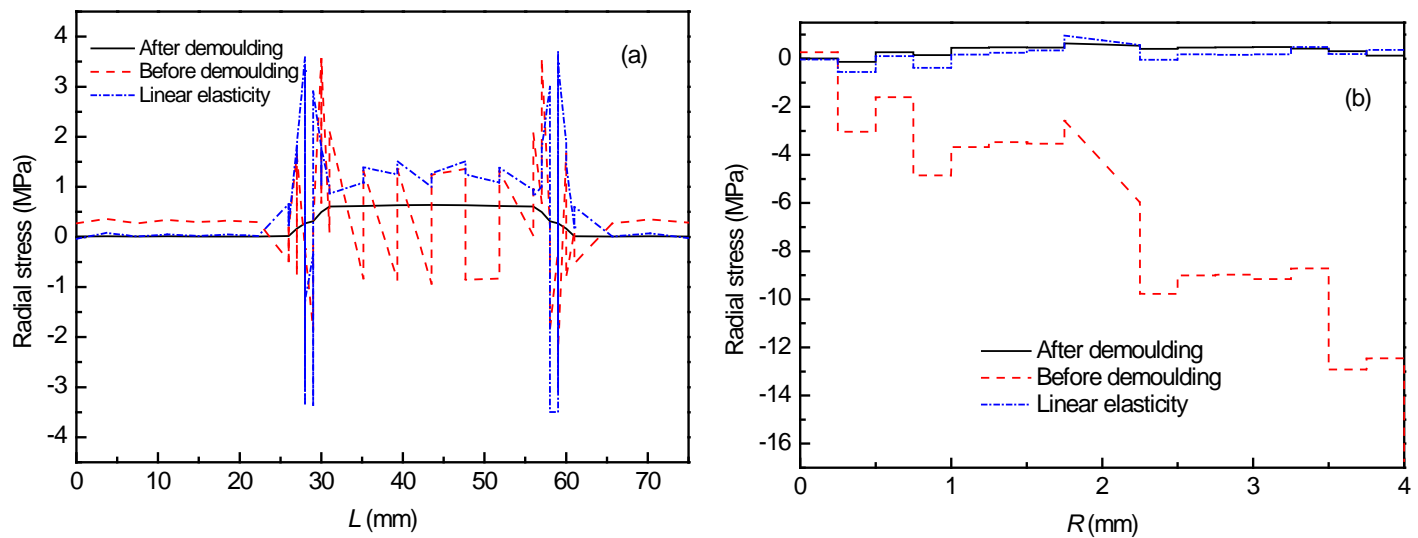

Fig.11. Radial stress versus axial (L1) and radial position with [90/0/-45/45/0/90]

lay up of boss.
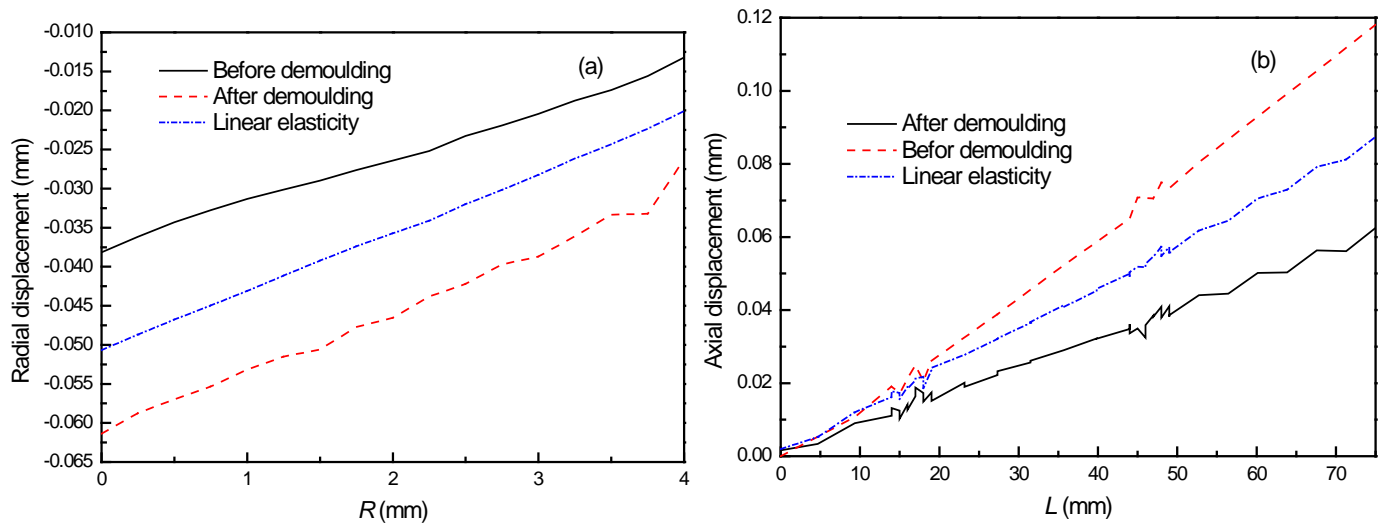

Fig.12. Warpage deformation versus radial and axial position with

[90/0/-45/45/0/90] lay up of boss. 